Check for updates

Cite this: J. Mater. Chem. B, 2020, 8, 1472

Received 10th October 2019

Accepted 19th January 2020

DOI: 10.1039/c9tb02225b

rsc.li/materials-b

\section{Sequential delivery of synergistic drugs by silica nanocarriers for enhanced tumour treatment $\dagger$}

\author{
Albane Birault, ${ }^{a}$ Simon Giret, ${ }^{a}$ Christophe Théron, ${ }^{a}$ Audrey Gallud, ${ }^{b}$ Afitz Da Silva, \\ Denis Durand, ${ }^{\mathrm{b}}$ Christophe Nguyen, (ID b Nadir Bettache, (iD b Magali Gary-Bobo, (ID b \\ John R. Bartlett, (D) ${ }^{c d}$ Michel Wong Chi Man (D) a and Carole Carcel (DD *a
}

\begin{abstract}
Herein hybrid silica nanoparticles have been engineered to direct the sequential delivery of multiple chemotherapeutic drugs in response to external stimuli such as variations in $\mathrm{pH}$. The nanocarriers consist of conventional MCM-41-type nanoparticles, which have been functionalised with an organic ligand (or stalk) grafted onto the external surface. The stalk is designed to "recognise" a complementary molecule, which serves as a "cap" to block the pores of the nanoparticles. First, camptothecin is introduced into the pores by diffusion prior to capping the pore apertures via molecular recognition. The cap, which is a derivative of 5-fluorouracil, serves as a second cytotoxic drug for synergistic chemotherapy. In vitro tests revealed that negligible release of the drugs occurred at $\mathrm{pH} 7.4$, thus avoiding toxic side effects in the blood stream. In contrast, the stalk/cap complex is destabilised within the endolysosomal compartment (pH 5.5) of cancer cells, where release of the drugs was demonstrated. Furthermore, this environmentally responsive system exhibited a synergistic effect of the two drugs, where the $\mathrm{pH}$-triggered release of the cytotoxic cap followed by diffusion-controlled release of the drug cargo within the pores led to essentially complete elimination of breast cancer cells.
\end{abstract}

\section{Introduction}

Combinatorial chemotherapy is widely employed as a primary treatment approach in cancer therapy to overcome the easilydeveloped defence of cancer cells against a single drug., However, conventional therapies involving the use of multiple free drugs often lead to well-known severe toxic side effects. ${ }^{2,3}$ One of the most effective approaches for overcoming such limitations is to load multiple therapeutic agents that exploit different anti-tumour mechanisms into a single effective nanocarrier with no drug leakage before reaching the target. Such smart nanocarriers could then increase the therapeutic efficiency and reduce toxic side effects by improving the bio-accessibility of drugs. ${ }^{4-8}$ In this sense, mesoporous silica nanoparticles (MSNPs) have been widely used, due to their versatility in forming the basis of stimuli-responsive drug delivery systems. ${ }^{9-13}$

\footnotetext{
${ }^{a}$ ICGM, Univ. Montpellier, CNRS, ENSCM, Montpellier, France.

E-mail: carole.carcel@enscm.fr

${ }^{b}$ Institut des Biomolécules Max Mousseron, UMR5247, Université de Montpellier, CNRS, ENSCM, Faculté de Pharmacie, 15 Avenue Charles Flahault, 34093, Montpellier, Cedex 05, France

${ }^{c}$ University of the Sunshine Coast, 90 Sippy Downs Drive, Sippy Downs QLD 4556, Australia

${ }^{d}$ Western Sydney University, Locked Bag 1797, Penrith, NSW, 2751, Australia $\dagger$ Electronic supplementary information (ESI) available. See DOI: 10.1039/ c9tb02225b
}

Notably, pH-responsive MSNPs provide the advantage of being endogenously stimulated due to the difference in $\mathrm{pH}$ between cellular compartments. ${ }^{14-16}$ We recently reported ${ }^{17}$ the use of molecular recognition via $\mathrm{H}$-bonding to design smart silica nanoparticles with a pH-activated cap, which exhibited slow release kinetics under slightly acidic conditions and good efficacy for cancer cells elimination.

In order to avoid the well-known phenomenon of anti-cancer drug resistance and to optimize this earlier nanosystem, the current work explored the design of a multi-drug nanoplatform for combined chemotherapy. Our strategy, outlined in Scheme 1, involves coupling silica nanocarriers embodying molecular recognition sites with an active cap to enhance the antitumour activity.

After loading the functionalised nanoparticles with camptothecin (CPT, Drug 1), the pores are closed to avoid premature release under physiological conditions within the bloodstream ( $\mathrm{pH} 7.4)$ using a 5-fluorouracil (5-FU) derivative (Drug 2), which can create stable H-bonds with Stalk located on the nanoparticles' surfaces. The opening of the pores is then triggered at the acidic $\mathrm{pH}$ within lysosomes ( $\mathrm{pH} 4.5-5.5)$, to deliver sequentially the two drugs within the cancer cells because of Stalk protonation followed by disruption of the Stalk-Cap bonds.

As already mentioned, there are a plethora of studies reporting MSNPs' efficacy for cancer therapy applications. ${ }^{18,19}$ Although some of these have described the use of drugs as pore-blockers 


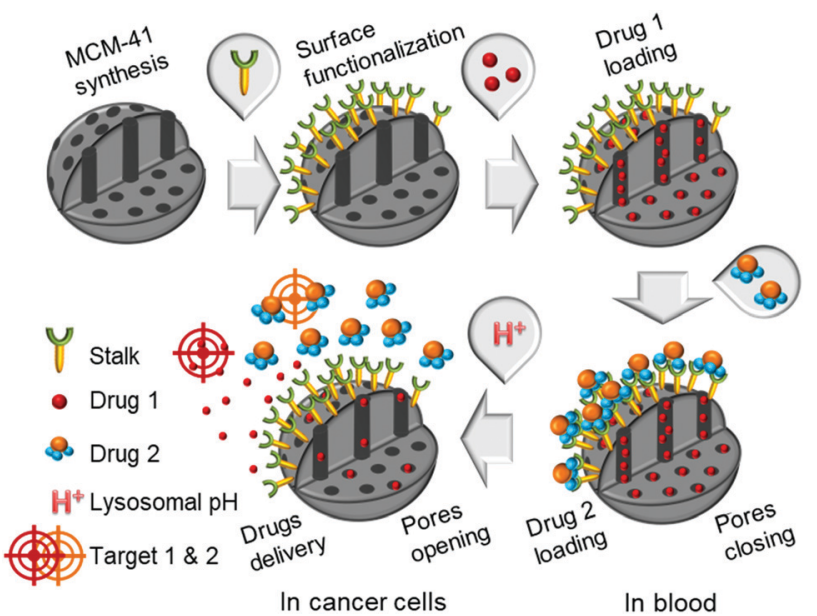

Scheme 1 Conceptual combinatorial drug delivery MSNP nanocarriers with Drug 1 (camptothecin) encapsulated inside the pores and Drug 2 (5-FU derivative) as the capping agent.

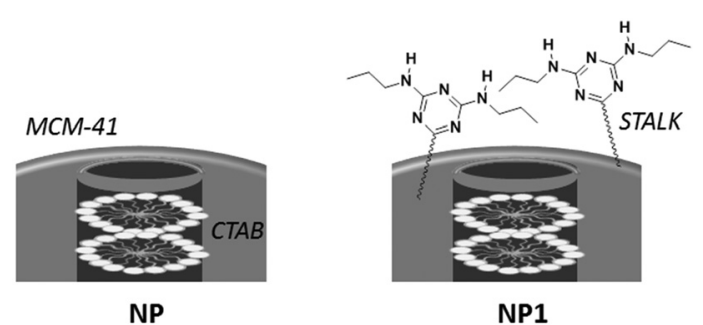

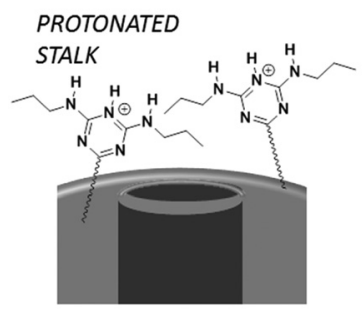

NP2

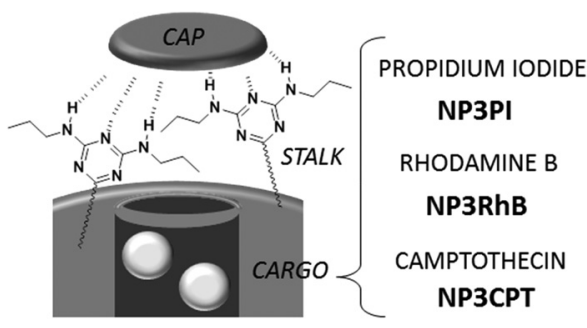

Scheme 2 Synthesis of capped nanoparticles.

to form promising nanocarriers for combination therapy, ${ }^{20-22}$ to the best of our knowledge, this is the first time that a $\mathrm{pH}$-responsive nanocarrier has been employed to exploit the synergistic toxicity of combining CPT and 5-FU for anti-cancer drug resistance applications.

To develop such systems, two separate syntheses are required: (1) the functionalisation of appropriate silica nanocarriers such as MCM-41, by Stalk grafting, to provide selective H-bonding recognition sites on the external surface; and (2) the synthesis of an antitumor derivative, with a complementary molecular recognition pattern, which, by pairing with the corresponding Stalks, would then cap the pores.

Organosilylated triazine derivatives, bearing donor-acceptordonor recognition sites, were used as Stalks condensed onto the surface of the nanoparticles. The Stalk employed in this study is tetrasilylated, which enhances the functionality of the platform by providing additional degrees of freedom and binding sites for grafting the ligand onto the surface of the nanoparticles, compared to our previously described bisilylated system. ${ }^{17}$ The additional conformational flexibility of the tetrasilylated Stalk would also be expected to enable the amine sites on the ligand to orient correctly to form the desired H-bonds with the Cap. As drug candidates, we chose for the pore-blocker a commonly used anticancer drug, 5-fluorouracil (5-FU), which exhibits complementary molecular recognition properties to Stalk. Previously, ${ }^{23}$ we have demonstrated that a derivative such as Cap (Fig. 1) with a three-fold $\mathrm{H}$-bonding pattern favours stable complexation at neutral $\mathrm{pH}$ in bulk hybrid silica materials. In contrast, the complex begins to dissociate at lower $\mathrm{pH}$ after triazine unit protonation, leading to the breakdown of $\mathrm{H}$-bonds initially involved in stabilization of the capping complex, thus promoting removal of Cap at pH 5.5 and below and its associated release. The biological activity of Cap was previously evaluated ${ }^{23}$ by cytotoxic assay on MCF-7 human breast cancer cells, showing a relatively high efficiency ( $43 \%$ of breast cancer cell death at $50 \mu \mathrm{M})$ for this molecule as an anticancer drug compared with the parent 5-FU ( $68 \%$ of cell death at $50 \mu \mathrm{M})$.

To investigate their viability and the combination therapeutic effect, we evaluated the cytotoxicity of these MSNPs towards human breast cancer cells (MCF-7). In a first study, the functionalised nanoparticles were loaded with fluorescent dyes, such as propidium iodide (PI) or rhodamine- $\mathrm{B}(\mathrm{RhB})$, to validate the opening of the pores in weakly-acidic lysosomal media and to assess the internalization of the MSNPs in the cells. In a second

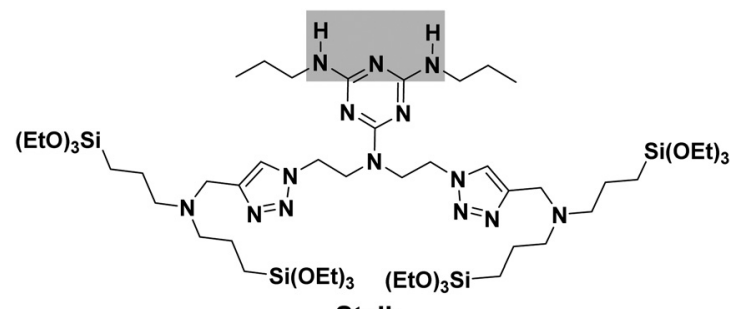

Stalk

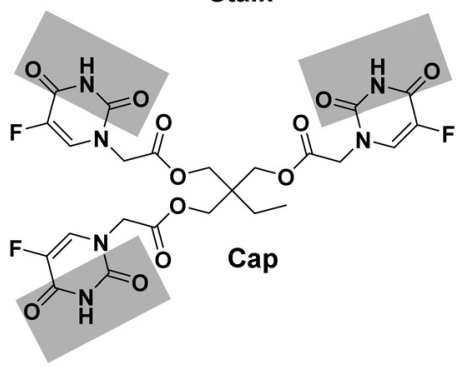

Fig. 1 Structures of Stalk precursor and Cap. 
study, the MSNPs were loaded with CPT and the pores capped with 5-FU derivative Cap to examine the overall cytotoxicity by in vitro studies. CPT destroys cancer cells via a different biological pathway than 5-FU ${ }^{24,25}$ and the two drugs have been previously shown to demonstrate a strong synergistic effect when used together to treat cancer cells. ${ }^{26}$ The approach outlined in this study enables two cytotoxic drugs to be delivered autonomously and sequentially, which is typically the manner in which injectionor drip-based combination drug therapies are administered to maximise the efficacy of such treatment. Under in vitro conditions, the multi-drug payload is retained under normal physiological conditions and then released autonomously at the disease site, demonstrating nearly complete cell apoptosis within $72 \mathrm{~h}$.

\section{Experimental section}

\section{General}

5-Fluorouracil, thionyl chloride, triethylamine and 1,1,1-tri(hydroxymethyl)propane were purchased from Sigma, USA and were used without purification. Solvents were dried by employing a MB SPS-800 apparatus.

\section{Characterization}

FTIR spectra were obtained on a PerkinElmer FT-IR Spectrum BX spectrometer. CPMAS solid-state NMR spectra were obtained using a Bruker FT-AM 400 spectrometer and ${ }^{1} \mathrm{H}$ - and ${ }^{13} \mathrm{C}-\mathrm{NMR}$ spectra were obtained using a Bruker AC-400 spectrometer, with $\mathrm{CDCl}_{3}$ or DMSO- $\mathrm{d}_{6}$ as solvent and tetramethylsilane (TMS) as a reference. $\mathrm{N}_{2}$ adsorption/desorption isotherms were obtained using a Micromeritics ASAP 2010 instrument at 77.15 K. Specific surface areas were calculated using the BET transform directly from the isotherms, using $0.162 \mathrm{~nm}^{2}$ as the cross-sectional area of $\mathrm{N}_{2}$. Electron micrographs were obtained with a JEOL 1200 EXII microscope for TEM and with a Hitachi S4800 $30 \mathrm{kV}$ apparatus for the SEM data. ${ }^{29} \mathrm{Si}$ solid-state NMR spectra were obtained using a Bruker DSX $300 \mathrm{MHz}$ spectrometer. Spectra were recorded using 4000 scans, with a relaxation delay of $3 \mathrm{~s}$, pulse duration of $6 \mu \mathrm{s}$ and acquisition time of $0.04 \mathrm{~s}$.

Thermogravimetric analyses (TGA) were performed on a Netzsch TG $209 \mathrm{C}$ apparatus employing a heating rate of $10{ }^{\circ} \mathrm{C} \mathrm{min}{ }^{-1}$ under an air flow of $20 \mathrm{~mL} \mathrm{~min}^{-1}$ up to $585{ }^{\circ} \mathrm{C}$. The small and wide-angle X-ray scattering (SWAXS) experiments were conducted using a Guinier Mering set up with a 2D image plate detector.

\section{Precursor synthesis}

Synthesis of 5-FUA. 5-FUA was prepared according to a previously reported method. ${ }^{27}$ Yield: 54\%; m.p. $274-276{ }^{\circ} \mathrm{C}$.

${ }^{1} \mathrm{H}$ NMR (400 MHz, DMSO-d 6 ): $\delta=11.93$ (s, 1H), 8.09 (d, 1H), $4.37 \mathrm{ppm}(\mathrm{s}, 2 \mathrm{H}) ;{ }^{13} \mathrm{C}$ NMR (100 MHz, DMSO-d $\left.{ }_{6}, \delta\right): \delta=168.6$, 158.2, 150.8, 140.1 128.2, 53.4; HRMS (ESI) $m / z:[\mathrm{M}+\mathrm{H}]^{+}$calcd for $\mathrm{C}_{6} \mathrm{H}_{6} \mathrm{~N}_{2} \mathrm{O}_{4} \mathrm{~F}$ : 189.0312; found: 189.0313.

Synthesis of Cap (Fig. 2). The synthesis of Cap was adapted from a previously reported procedure. ${ }^{22}$ 5-FUA $(1.1 \mathrm{~g}, 5.85 \mathrm{mmol})$ and triethylamine $(126 \mu \mathrm{L}, 0.904 \mathrm{mmol})$ were dissolved in dry

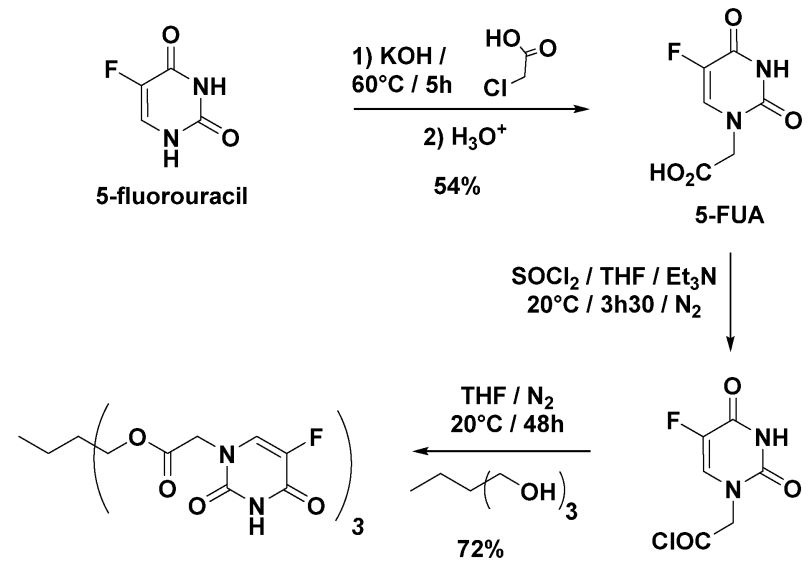

Fig. 2 Optimized synthesis of Cap.

THF (44 mL) and freshly distilled $\mathrm{SOCl}_{2}(8.4 \mathrm{~mL})$ at $20{ }^{\circ} \mathrm{C}$ under $\mathrm{N}_{2}$. After $3.5 \mathrm{~h}$, excess $\mathrm{SOCl}_{2}$ and THF were removed under vacuum and the residue was re-dissolved in dry THF (42 $\mathrm{mL})$. 1,1,1-Tri(hydroxymethyl)propane $(80 \mathrm{mg}, \quad 0.60 \mathrm{mmol})$ was added and the mixture was stirred at $20{ }^{\circ} \mathrm{C}$ for $48 \mathrm{~h}$. The solvent was then evaporated, and the residue was purified by column chromatography $\left(\mathrm{CH}_{2} \mathrm{Cl}_{2} / \mathrm{MeOH}\right.$ : $98: 2$ 90:10). Yield: 72\%; m.p. decomposition after $180{ }^{\circ} \mathrm{C}$.

${ }^{1} \mathrm{H}$ NMR (400 MHz, DMSO-d 6 ): $\delta=12.00(\mathrm{~s}, 3 \mathrm{H}), 8.04(\mathrm{~d}, 3 \mathrm{H})$, $4.50(\mathrm{~s}, 6 \mathrm{H}), 4.05(\mathrm{~s}, 6 \mathrm{H}), 1.36(\mathrm{q}, 2 \mathrm{H}), 0.79 \mathrm{ppm}(\mathrm{t}, 3 \mathrm{H}) ;{ }^{13} \mathrm{C} \mathrm{NMR}$ (100 MHz, DMSO-d $\left.\mathrm{d}_{6}\right): \delta=20.9$, 34.7, 48.7, 63.4, 130.1, 138.1, 140.5, 149.6, 157.2, 167.6 ppm; HRMS (ESI) $m / z:[\mathrm{M}+\mathrm{H}]^{+}$calcd for $\mathrm{C}_{24} \mathrm{H}_{24} \mathrm{~N}_{6} \mathrm{O}_{12} \mathrm{~F}_{3}$ : 645.1404; found: 645.1412.

Synthesis of Stalk (Fig. 3). The Stalk was prepared according to a previously reported procedure. ${ }^{28}$ Firstly, compound 1 was added dropwise (due to its potentially-explosive nature, care

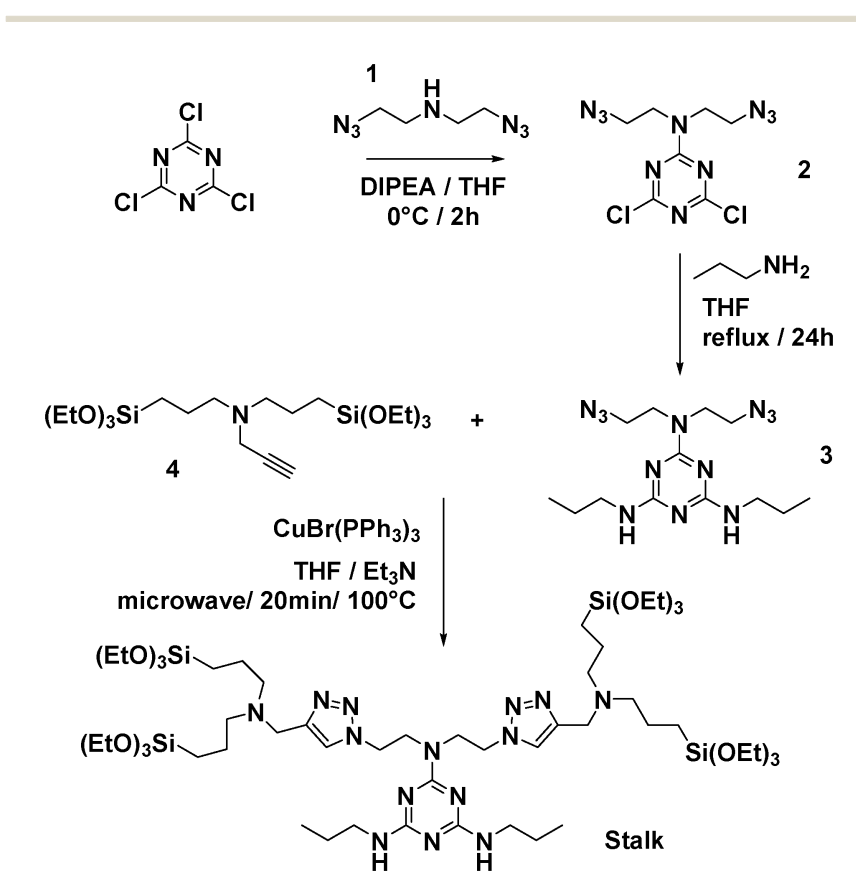

Fig. 3 Synthesis of Stalk. 
should be taken) to a solution of cyanuric chloride in THF in the presence of $\mathrm{N}, \mathrm{N}$-diisopropylethylamine (DIPEA) at $0{ }^{\circ} \mathrm{C}$, to afford 2 (66\% yield). Compound 2 was then dissolved in THF with 10 equivalents of propylamine under reflux to give 3 (90\% yield). Finally, the tetrasilylated Stalk was obtained via a CuAAC Click coupling reaction between 3 and 4 . The reagents were introduced into a microwave oven in the presence of the $\mathrm{CuBr}\left(\mathrm{PPh}_{3}\right)_{3}$ catalyst and $\mathrm{Et}_{3} \mathrm{~N}$ in THF at $100{ }^{\circ} \mathrm{C}$ for 20 minutes to yield the Stalk (Fig. S1, ESI $\dagger$ ) in quantitative yield.

${ }^{1} \mathrm{H}$ NMR (400 MHz, $\mathrm{CDCl}_{3}$, Fig. S1, ESI $\left.\dagger\right): \delta=0.56(\mathrm{t}, 8 \mathrm{H})$, $0.95(\mathrm{t}, 6 \mathrm{H}), 1.22(\mathrm{t}, 36 \mathrm{H}), 1.58(\mathrm{~m}, 12 \mathrm{H}), 2.39(\mathrm{t}, 8 \mathrm{H}), 3.29$ $(\mathrm{q}, 4 \mathrm{H}), 3.64(\mathrm{~m}, 8 \mathrm{H}), 3.80(\mathrm{q}, 24 \mathrm{H}), 4.47(\mathrm{t}, 4 \mathrm{H})$, and $7.32(\mathrm{~s}, 2 \mathrm{H})$. ${ }^{13} \mathrm{C} \mathrm{NMR}\left(100 \mathrm{MHz}, \mathrm{CDCl}_{3}\right): \delta=7.86(\mathrm{~s}), 11.50(\mathrm{~s}), 18.28(\mathrm{~s})$, 20.26 (s), 23.05 (s), 42.47 (s), 45.90 (s), 48.16 (s), 48.60 (s), 56.46 (s), 58.29 (s), $123.11(\mathrm{~s}), 128.51$ (s), and 132.01 (s). HRMS (ESI) $m / z:[\mathrm{M}+\mathrm{H}]^{+}$calcd for $\mathrm{C}_{55} \mathrm{H}_{115} \mathrm{~N}_{14} \mathrm{O}_{12} \mathrm{Si}_{4}(\mathrm{MH})$ : 1275.7896; found: 1275.7910 .

\section{Nanoparticles preparation (Scheme 2)}

Synthesis of NP. Cetyltrimethylammonium bromide (CTAB; $\left.315 \mathrm{mg}, 8.6 \times 10^{-1} \mathrm{mmol}\right)$, was dissolved in Milli Q $\mathrm{H}_{2} \mathrm{O}(150 \mathrm{~mL}$, $8.3 \times 10^{3} \mathrm{mmol}$ ), and the $\mathrm{pH}$ was adjusted to $\sim 12$ by addition of $\mathrm{NaOH}$ solution $(2 \mathrm{M}, 1.1 \mathrm{~mL})$. After heating the resulting solution to $80{ }^{\circ} \mathrm{C}$, tetraethylorthosilicate (TEOS; $1.4 \mathrm{~mL}, 6.3 \mathrm{mmol}$ ) was added dropwise and the reaction was continued for $2 \mathrm{~h}$ to yield MCM-41 nanoparticles. Finally, the nanoparticles were collected after centrifugation and washing with EtOH. ${ }^{29} \mathrm{Si}$ CPMAS solid-state NMR: $\delta=-99.2,-108.9 \mathrm{ppm}$.

Synthesis of NP1. Stalk ( $80 \mathrm{mg}, 0.10 \mathrm{mmol}$ ) was added to a suspension of MCM-41 (80 mg) (pre-heated overnight at $90{ }^{\circ} \mathrm{C}$ to remove traces of $\mathrm{H}_{2} \mathrm{O}$ and to activate $\mathrm{Si}-\mathrm{OH}$ functions) in dry toluene $(10 \mathrm{~mL})$ under an inert atmosphere. The suspension was then heated at $80{ }^{\circ} \mathrm{C}$ for $24 \mathrm{~h}$, prior to centrifuging the nanoparticles and washing them twice with ethanol and then five times with water. ${ }^{29} \mathrm{Si}$ CPMAS NMR: $\delta=-57.4,-100.1$, -108.9 ppm.

Synthesis of NP2. The CTAB surfactant was removed by washing with a solution of $\mathrm{HCl} 37 \mathrm{wt} \%(1 \mathrm{~mL})$ in ethanol (80 $\mathrm{mL}$ ) under reflux overnight. The resulting NP2 nanoparticles were washed twice with EtOH.

Synthesis of NP3. Excess $\mathrm{HCl}$ associated with the NP2 nanoparticles was removed by washing the nanoparticles with freshly distilled $\mathrm{Et}_{3} \mathrm{~N}(1 \mathrm{~mL}, 7.2 \mathrm{mmol})$ in $\mathrm{H}_{2} \mathrm{O}\left(10 \mathrm{~mL}, 5.6 \times 10^{2} \mathrm{mmol}\right)$ for $48 \mathrm{~h}$ at $70{ }^{\circ} \mathrm{C}$. The resulting NP3 nanoparticles were then washed two times with $\mathrm{H}_{2} \mathrm{O}$ and three times with EtOH.

\section{Loading, capping and release}

NP3 nanoparticles were suspended in a solution of cargo molecules as described below. The suspension was then sonicated for $20 \mathrm{~min}$ and stirred for $18 \mathrm{~h}$ to promote filling of the pores with the cargo molecules. To ensure retention of the drug, the pore apertures were capped by addition of Cap ( $3 \mathrm{mg} ; 4.7 \times 10^{-3} \mathrm{mmol}$ ) and the suspension was stirred for an additional $48 \mathrm{~h}$. After centrifugation, the particles were washed with DMSO around 5-6 times following by washing with water and $\mathrm{EtOH}$.
NP3PI ( $5 \mathrm{mM})$ : PI (45 mg, $\left.6.7 \times 10^{-2} \mathrm{mmol}\right)$ in water $(13.5 \mathrm{~mL})$, and nanoparticles (90 $\mathrm{mg})$.

NP3RhB $(5 \mathrm{mM}): \operatorname{RhB}\left(32 \mathrm{mg}, 6.7 \times 10^{-2} \mathrm{mmol}\right)$ in water (13.5 mL), and nanoparticles ( $90 \mathrm{mg})$.

NP3CPT (3 mM): CPT (15 mg, $\left.4.3 \times 10^{-2} \mathrm{mmol}\right)$ in DMSO (15 mL), and nanoparticles (90 mg).

The CPT loadings obtained under the conditions used to impregnate the NP3 nanoparticles were $4 \mathrm{wt} \%$, on the basis of visible absorbance spectroscopy studies.

The release of the CPT from NP3CPT mesopores was evaluated by UV-Vis absorbance at $380 \mathrm{~nm}$ at either $\mathrm{pH} 2,5.5$ or 7.4 for different periods of time over a $24 \mathrm{~h}$ period. For these studies, $3 \mathrm{mg}$ of NP3CPT was dispersed into $1 \mathrm{~mL}$ of aqueous solution at the defined $\mathrm{pH}$ and then $100 \mu \mathrm{L}$ aliquots of the nanoparticle dispersion were poured into Eppendorf tubes. The tubes were stirred during release of the drug and were then centrifuged $\left(15 \times 10^{3} \mathrm{~min}^{-1}, 15 \mathrm{~min}\right)$. The resulting supernatant was placed into a microreader plate and the concentration of drug was determined from an appropriate calibration curve.

\section{In vitro studies}

Cell culture conditions. Human breast cancer cells (MCF-7) were purchased from ATCC (American Type Culture Collection, Manassas, VA). MCF-7 cells were cultured in DMEM-F12 culture medium supplemented with $10 \%$ foetal bovine serum and $50 \mu \mathrm{g} \mathrm{mL}{ }^{-1}$ gentamycin. These cells were allowed to grow in a humidified atmosphere at $37{ }^{\circ} \mathrm{C}$ under $5 \% \mathrm{CO}_{2}$.

\section{Cytotoxicity}

MCF-7 cells were seeded into 96-well plates at $10^{4}$ cells per well in $200 \mu \mathrm{L}$ culture medium and allowed to grow for $24 \mathrm{~h}$. The three batches of nanoparticles (NP, NP3RhB, and NP3CPT) were dispersed in ethanol at a concentration of $10^{-2} \mathrm{M}$ and sonicated in an ultrasonic bath until completely dispersed. Then, cells were incubated for $72 \mathrm{~h}$ with different nanoparticle concentrations (from 1 to $100 \mu \mathrm{g} \mathrm{mL}^{-1}$ ). For the NP3CPT batch, the experiment was also carried out for shorter lengths of time $(6,16$ and $24 \mathrm{~h})$. At the end of the incubation time, a MTT assay was performed to evaluate the toxicity. Briefly, cells were incubated for $4 \mathrm{~h}$ with $0.5 \mathrm{mg} \mathrm{mL}{ }^{-1}$ of MTT (3-(4,5-dimethylthiazol-2yl)-2,5-diphenyltetrazoliumbromide; Promega) in culture media. The MTT/media solution was then removed, and the precipitated crystals were dissolved in EtOH/DMSO (1:1). The solution absorbance was read at $540 \mathrm{~nm}$.

\section{Confocal imaging}

MCF-7 cells were seeded one day prior to nanoparticle exposure at $10^{6}$ cells per $\mathrm{cm}^{2}$ in glass-bottomed culture dishes from Ibidi Biovalley ${ }^{\circledR}$. Cells were then exposed for $20 \mathrm{~h}$ to $40 \mu \mathrm{g} \mathrm{mL}^{-1}$ of NPs. Prior to imaging, the cells were stained with $50 \mathrm{nM}$ LysoTracker Green DND-26 for $30 \mathrm{~min}$ and $5 \mu \mathrm{g} \mathrm{mL}{ }^{-1}$ Hoechst 33342 was added during the last $10 \mathrm{~min}$ of incubation. Confocal images were acquired on a Zeiss Axio Observer confocal microscope equipped with an oil-immersion Plan-Apochromat $63 \times / 1.40$ objective. 


\section{Flow cytometry}

MCF-7 cells were seeded into a 6-well plate (Nunc; $10^{6}$ cells per well) and allowed to grow for $24 \mathrm{~h}$. The cells were harvested at 5 , 18 and $22 \mathrm{~h}$ following NP exposure $\left(40 \mu \mathrm{g} \mathrm{mL} \mathrm{m}^{-1}\right)$ and resuspended in DMEM-F12 phenol red-free medium. Dead cells were counterstained with $4^{\prime}$,6-diamidino-2-phenylindole (DAPI, $\left.0.5 \mu \mathrm{g} \mathrm{mL}{ }^{-1}\right)$. The percentage of positive living cells for NP uptake was determined on a FACS Canto II flow cytometer. The data were analysed with Win MDI software v2.8.

\section{Results and discussion}

\section{Preparation of precursors}

The approach used to prepare the Stalk (Fig. 3 and Fig. S1, ESI $\dagger$ ) was based on a previously reported method. ${ }^{28}$

Similarly, the Cap was prepared according to an optimised protocol based on a previously reported synthesis. ${ }^{23}$ The reaction was performed in homogeneous medium and employed an eco-friendly room-temperature approach for the second and third steps, which led to an increased yield and a reduction in the overall reaction time (Fig. 2).

\section{Nanoparticle synthesis, functionalisation, loading and capping}

MCM-41 nanoparticles (NP) were prepared by classical sol-gel processing in alkaline aqueous solution. CTAB used to template the compact hexagonal porosity (Fig. S2, ESI $\dagger$ ) in the MSNPs was retained in the pores, and the Stalk was then covalently grafted onto the MSNP surface by condensation. After washing with water, the resulting nanoparticles NP1 were characterised by IR spectroscopy and solid-state ${ }^{29} \mathrm{Si}$ NMR to demonstrate successful functionalisation.

As shown in Fig. 4(A), bands arising from the Stalk in the spectrum of NP1 are observed at 1557 and $1498 \mathrm{~cm}^{-1}$, which are associated with $-\mathrm{N}=\mathrm{N}$ and $\mathrm{C}=\mathrm{C}$ stretching vibrations. ${ }^{29}$ Notably, these vibrations are not evident in the corresponding NP spectrum. In the region from 2700 to $3100 \mathrm{~cm}^{-1}$ (Fig. 4(B)) the spectra of NP and NP1 are similar and are dominated by bands associated with CTAB at 2854 and $2924 \mathrm{~cm}^{-1}$. Hence the spectral features of Stalk are not clearly observed, except for a
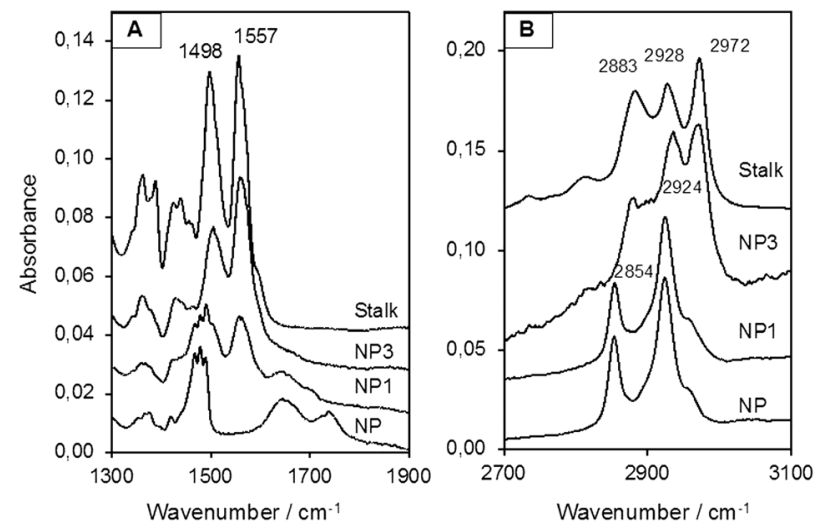

Fig. $4 \mathrm{IR}$ spectra (A) from 1300 to $1900 \mathrm{~cm}^{-1}$ and (B) from 2700 to $3100 \mathrm{~cm}^{-1}$ of NPs and the Stalk precursor. shoulder at $2972 \mathrm{~cm}^{-1}$. CTAB, initially retained within the pores to maximize functionalisation on the external surface, was then extracted with $\mathrm{HCl}$ to afford NP2. Excess $\mathrm{HCl}$ remaining after extraction of CTAB was neutralised by suspending NP2 in an aqueous solution of $\mathrm{Et}_{3} \mathrm{~N}$ and stirring the resulting mixture for $48 \mathrm{~h}$ at $70{ }^{\circ} \mathrm{C}$, before centrifugation and washing to give NP3. CTAB elimination was confirmed by the disappearance of its associated bands at 2854 and $2924 \mathrm{~cm}^{-1}$ in the IR spectrum of NP3. In addition, the loss of bands associated with Stalk ethoxy species at 1388 and $1439 \mathrm{~cm}^{-130}$ in the spectrum of NP3 (Fig. 4(A)) is consistent with successful grafting of Stalk onto the surface of NP3. Similarly, the decrease in the relative intensities of the Stalk bands at 2883 and $2972 \mathrm{~cm}^{-1}$, which include contributions from $\nu_{\mathrm{s}}\left(\mathrm{CH}_{3}\right)$ and $\nu_{\mathrm{as}}\left(\mathrm{CH}_{3}\right)$, respectively, of ethoxy groups, ${ }^{30}$ is consistent with loss of ethoxy species following grafting.

The solid-state ${ }^{29} \mathrm{Si}$ NMR spectrum of NP1 (Fig. 5(B)) also demonstrated the successful grafting of the Stalk, with two sets of chemical shifts being evident. The first set, at $-47,-57$ and $-67 \mathrm{ppm}$, are attributed to $\mathrm{T}^{1}, \mathrm{~T}^{2}$ and $\mathrm{T}^{3}$ sites, respectively, arising from the Stalk and are not observed in the spectrum of NP (Fig. 5(A)), as expected. The relatively high intensity of the $\mathrm{T}^{2}$ signal compared to that of the $\mathrm{T}^{3}$ signal indicates that condensation of the ethoxy/hydroxy species on the Stalk is

(A)

(B)

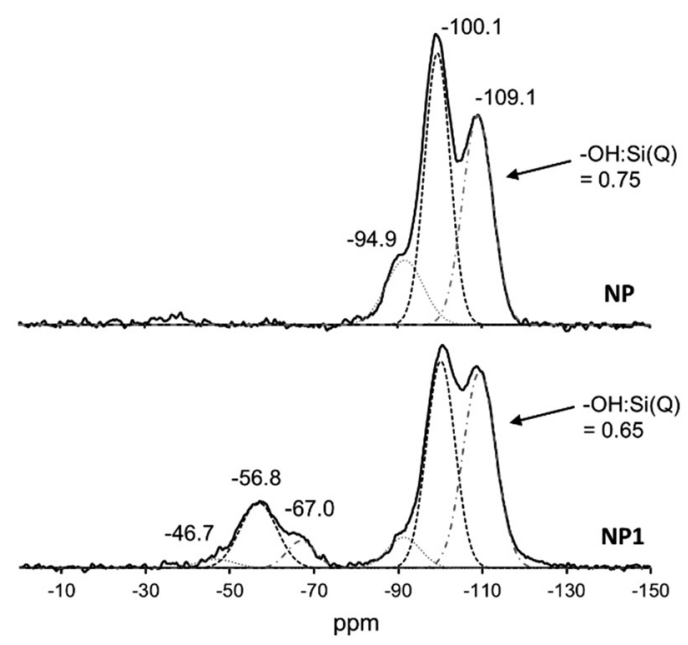

(C)

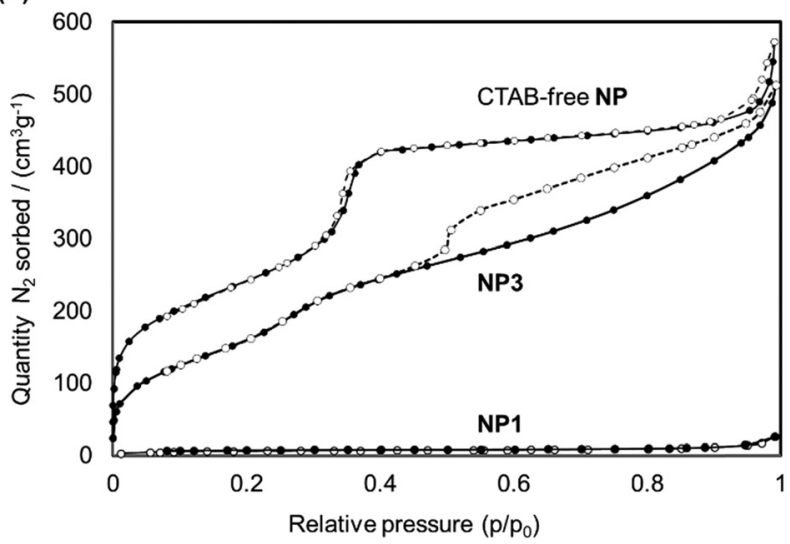

Fig. 5 Solid state ${ }^{29} \mathrm{Si}$ NMR spectra of NP (A) and NP1 (B). (C) Isotherms of CTAB-free NP, NP1 and NP3 obtained by nitrogen sorption analyses. 
incomplete after grafting, with some of the four Si sites in the grafted Stalk moieties being bound to the surface of the nanoparticles via two oxo bonds instead of three. The second set of peaks in the ${ }^{29} \mathrm{Si}-\mathrm{NMR}$ spectra, at $-95,-100$ and $-109 \mathrm{ppm}$, are assigned to $\mathrm{Q}^{2}, \mathrm{Q}^{3}$ and $\mathrm{Q}^{4}$ species, respectively, within the MCM-41 framework. The increase in the relative intensity of the $\mathrm{Q}^{4}$ signal for NP1, and the corresponding decrease in the $-\mathrm{OH}$ : Si ratio for the $\mathrm{Q}^{n}$ species following grafting (from 0.75 to $0.65)$, is associated with conversion of $Q^{2}$ and $Q^{3}$ species to $Q^{4}$ species during functionalisation. Thermogravimetric analysis (TGA) confirmed the presence of the organic Stalk on the surface of the MCM-41 nanoparticles (Fig. S3, ESI $\dagger$ ).

The $\mathrm{N}_{2}$ adsorption/desorption isotherms of NP1 (grafted nanoparticles containing CTAB) are compared with those of CTAB-free NP and NP3 in Fig. 5(C). As expected, NP1 exhibits very low accessibility to small molecules such as $\mathrm{N}_{2}$, with a corresponding $\mathrm{BJH}$ adsorption pore volume and BET surface area of $0.03 \mathrm{~cm}^{3} \mathrm{~g}^{-1}$ and $21 \mathrm{~m}^{2} \mathrm{~g}^{-1}$, respectively, consistent with the presence of $\mathrm{CTAB}$ within the mesopores. In contrast, removal of CTAB by washing yields a mesoporous material (Type IV isotherm) with a pore volume of $0.92 \mathrm{~cm}^{3} \mathrm{~g}^{-1}$ and BET surface area of $902 \mathrm{~m}^{2} \mathrm{~g}^{-1}$. The isotherm of CTAB-free NP shows a steep increase near $P / P_{0}=0.35$, consistent with the presence of ordered mesopores. The corresponding data for NP3 are also consistent with a highly porous material, albeit with a smaller pore volume $\left(0.72 \mathrm{~cm}^{3} \mathrm{~g}^{-1}\right)$ and surface area $\left(675 \mathrm{~m}^{2} \mathrm{~g}^{-1}\right)$ than the unfunctionalised material NP. A slight increase in the adsorption branch at $p / p_{0}$ around 0.3 for NP3 is consistent with smaller pore size than in the CTAB-free NP. More significantly, the isotherm of NP3 has a distinct hysteresis with non-parallel branches on the adsorption and desorption arms. Such profiles are often observed for porous samples having ink-bottle type pores, consistent with modification of the external surface in the vicinity of the pore openings. These data suggest that functionalisation leads to some obstruction of the nanoparticle porosity, although the pore network is still highly accessible to small molecules such as $\mathrm{N}_{2}$.

To load the functionalised nanoparticles with a drug cargo, NP3 was suspended with several different cargos, including $\mathrm{RhB}$, PI or CPT in water or DMSO. Cap was then added to the suspension to complex the Stalks on the surface and thus block the pores. The suspension was stirred at RT for a further $48 \mathrm{~h}$ and then centrifuged. The resulting nanoparticles were vigorously washed with DMSO (until a transparent supernatant was obtained) to remove adsorbed cargo that had not been incorporated within the pores prior to capping and residual physisorbed Cap. After additional washings with water and EtOH, the nanoparticles were dried under vacuum to give the NP3RhB, NP3PI or NP3CPT nanomaterials, depending on the cargo compound used.

The quantity of Cap complexed by Stalk in the NP3 system was assessed by monitoring the relative quantities of $\mathrm{Si}, \mathrm{N}$ and $\mathrm{F}$ in the NP3CPT system via energy dispersive X-ray (EDX)-TEM analysis. The results obtained are illustrated in Fig. 6 and Fig. S4 (ESI $\dagger$ ). The semi-quantitative EDX analysis revealed significant quantities of $\mathrm{F}$ atoms (Fig. S4, ESI $\dagger$ ) arising from
(A)
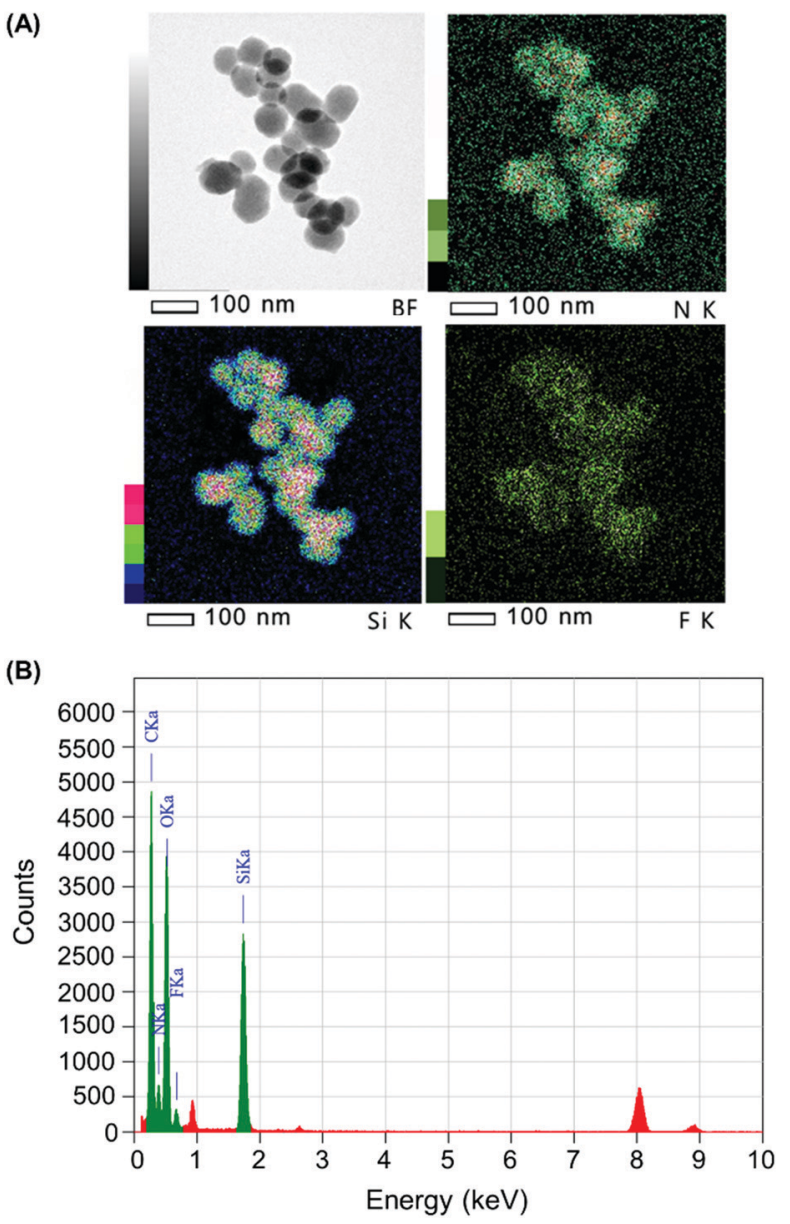

Fig. 6 (A) Bright field (BF) and elemental mapping ( $\mathrm{Si}, \mathrm{N}$ and F) and (B) EDX spectrum of NP3CPT by EDX-TEM.

the presence of surface-complexed Cap. In addition, the relative quantities of Si, $\mathrm{N}$ and $\mathrm{F}$ atoms (Fig. S4, ESI $\dagger$ ), together with the relative masses of $\mathrm{SiO}_{2}$ and Stalk determined by TGA (Fig. S3, ESI $\dagger$ ), are consistent with a Stalk: Cap molar ratio of $3: 1$ and a CPT loading of $4.0 \mathrm{wt} \%$ in the NP3CPT system. The data also reveal the presence of three Stalk (and hence one Cap) per $100 \mathrm{Si}$ atoms (see ESI $\dagger$ ). This is consistent with the expected complexation between the complementary Stalk and Cap and the associated obstruction of the MSNP pore apertures in NP3CPT.

In addition, the size and morphology of the nanoparticles were characterized at different stages during the synthesis to verify their uniformity. SEM and TEM micrographs of NP, NP3 and NP3CPT (Fig. 7A) showed relatively mono-dispersed nanoparticles with diameters ranging from 110 to $200 \mathrm{~nm}$. The TEM images also revealed the expected transverse porosity in the materials. A comparison of the nanoparticle size obtained by SEM with that observed in solution via DLS studies (Fig. 7B) indicates that the functionalised nanoparticles are essentially unaggregated after being dispersed in solution, with relatively small polydispersity indices. As expected, the data indicate that functionalisation of NP with Stalk, to form NP3, results in a small increase in the hydrodynamic diameter of the nanoparticles (from 140 to $\sim 190 \mathrm{~nm}$ ) without any increase in 

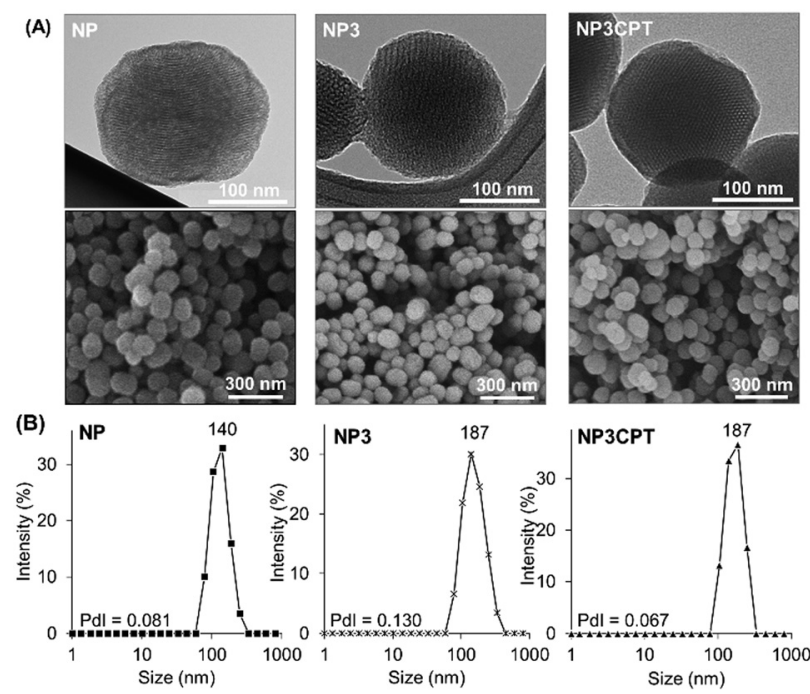

Fig. 7 (A) TEM and SEM images and (B) DLS measurements of NP, NP3 and NP3CPT, nanomaterials. The polydispersity indices (Pdl, measured by DLS) are included.

polydispersity, consistent with functionalisation of the particles by Stalk. The size and low polydispersity of NP3 remain unchanged after impregnation with CPT (to form NP3CPT).

Consequently, the resulting drug loaded NP3CPT have a suitable size for nanomedicine applications.

Thereafter, the stability of the Stalk-Cap complex as a function of $\mathrm{pH}(2,5.5$ or 7.4) was investigated in the case of NP3CPT by monitoring CPT release in solution via UV-Vis absorbance at $380 \mathrm{~nm}$ (Fig. 8). The data indicated that only about $5 \%$ of the drug is released at neutral $\mathrm{pH}$, confirming that sufficient Stalk-Cap bonds remain intact to ensure that the nanoparticles can efficiently transport the chemotherapeutic agents within the blood stream without premature release of the payload.

In contrast, around $38 \%$ of CPT was released at pH 5.5 after $24 \mathrm{~h}$. This $\mathrm{pH}$ was chosen to mimic that present within the endosomal compartments, and the results suggest that release of the cargo and Cap would be expected to occur within the endosomal regions. As expected, essentially quantitative release of Cap is observed at pH 2 after only a few hours. This result demonstrates that the removal of the chemotherapeutic Cap and subsequent release of the second drug loaded within the pores is controlled by environmental $\mathrm{pH}$. Our earlier studies of the release of Cap confirm that its release concentration profile is similar to that of CPT.

\section{In vitro studies on MCF-7 breast cancer cells}

Kinetic study. For kinetic studies, MCF-7 cells were incubated at $37{ }^{\circ} \mathrm{C}$ for varying time intervals with $40 \mu \mathrm{g} \mathrm{mL} \mathrm{m}^{-1}$ of NP3PI. The nanoparticle internalisation was detected by flow cytometry after co-staining with DAPI to exclude dead cells, and the results presented below represent the averages calculated from three independent experiments. As shown in Fig. 9(A), the internalisation was relatively fast, with $50 \%$ of MCF-7 cells containing nanoparticles after $20 \mathrm{~h}$. This result confirmed that
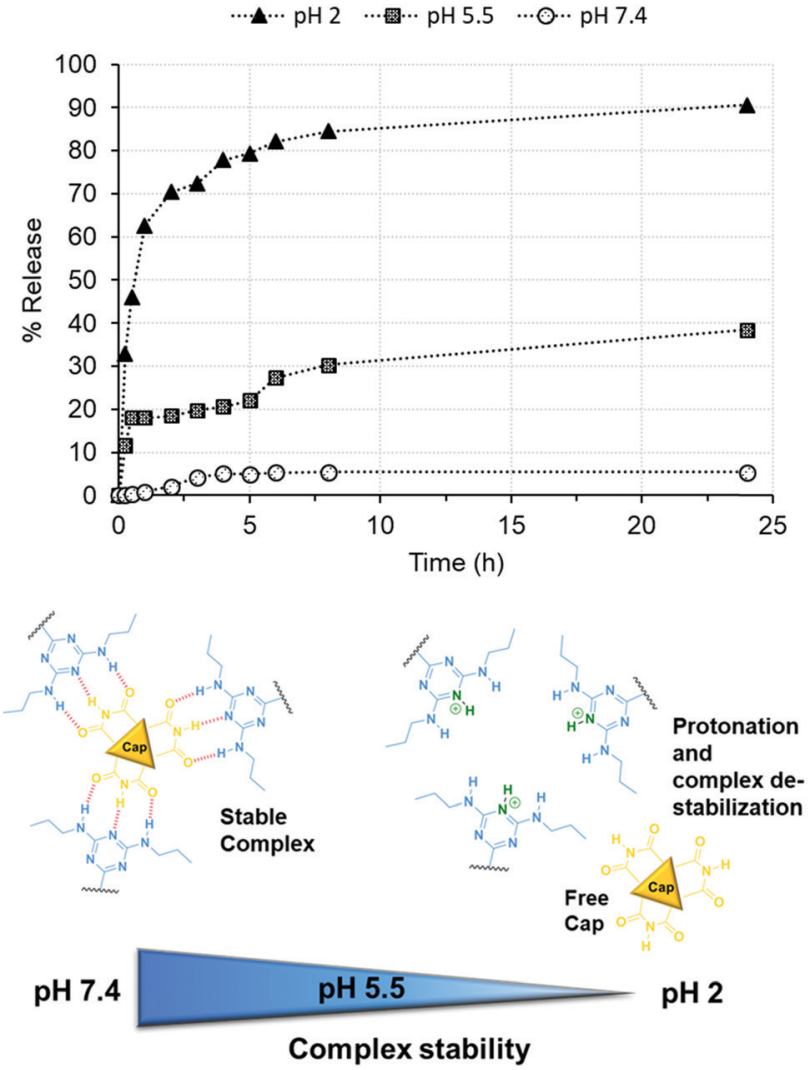

Fig. 8 Release of CPT from NP3CPT mesopores (determined by UV/Vis absorbance spectroscopy) as function of $\mathrm{pH}$.

the size and nature of the nanoparticles were suitable for penetrating MCF-7 cancer cells. In addition, it is important to note that, for this measurement, only living cells were considered, and since our cap is biologically active, it might lead to the death of some cells that would be not detected by the approach used here. Hence, the values reported in Fig. 9(A) represent a lower limit for the apparent rate of internalisation.

\section{Uptake of nanoparticles in MCF-7 cells - confocal microscopy}

To assess the uptake of nanoparticles in MCF-7 breast cancer cells, the cells were incubated for $20 \mathrm{~h}$ with $40 \mu \mathrm{g} \mathrm{mL} \mathrm{m}^{-1}$ of NP3RhB and NP3PI (Fig. 9(B)). The endolysosomal compartments were labelled with the green lysotracker and the nuclei marked in blue with the Hoechst stain. The control images correspond to cells that have not been incubated with nanoparticles. In culture cells incubated with NP3PI, we can detect the presence of PI in red, and the yellow regions observed in the merged picture demonstrate the co-localisation of NP3PI with endo-lysosomal compartments (see yellow arrows in Fig. 9(B)). This validates the internalisation of nanoparticles by the endocytosis pathway. In addition, when culture cells were incubated with nanoparticles loaded with RhB (NP3RhB), which is known to cross the cell membranes (and lysosome), we observed that the red dye fully stained the cytoplasm (see white arrows in Fig. 9(B)), confirming the release of the cargo molecules once the nanocarriers have entered the lysosomes. Overall, these 
(A)

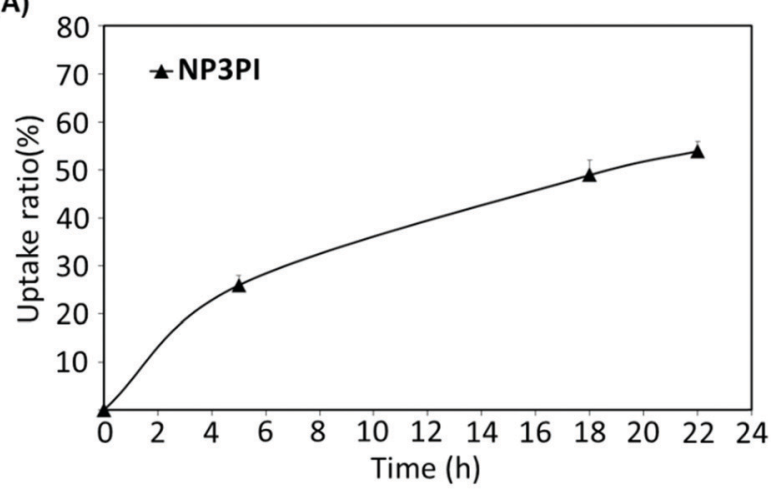

(B)

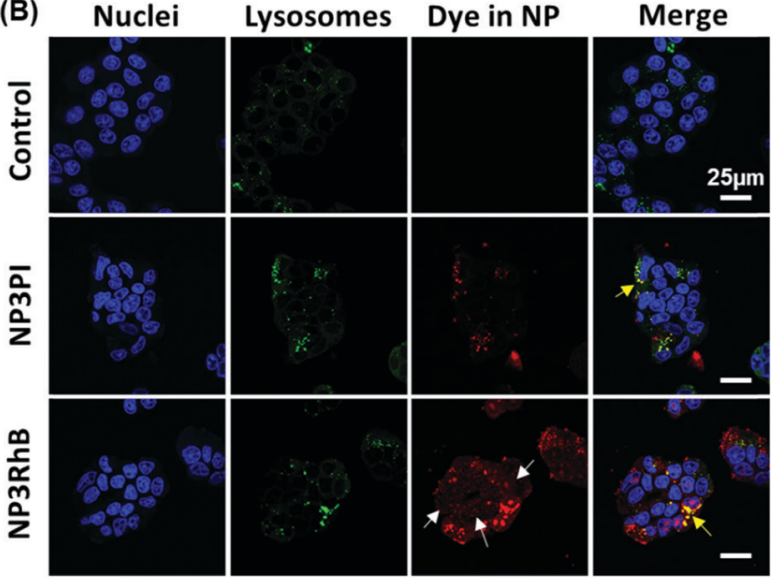

Fig. 9 (A) Internalisation rate in MCF-7 cells using NP3PI. Error bars show standard deviation. (B) Confocal microscopy of control (top), NP3PI (middle) and NP3RhB (bottom) after $20 \mathrm{~h}$ of incubation in a culture medium of MCF-7 cells.

data confirm (1) the uptake of the nanomaterials by the cell via the endolysosomal pathway and (2) that the release of active drug molecules is triggered at lysosomal $\mathrm{pH}$, consistent with the $\mathrm{pH}$-sensitivity data included in Fig. 8.

\section{Cytotoxicity}

The cytotoxicity of the new nanocarrier on MCF-7 breast cancer cells was then assessed via MTT assays. This study was performed with NP3RhB to determine the action of the cytotoxic 5-FU cap (RhB is known to be inactive ${ }^{31}$ ) and with NP3CPT to determine if the cytotoxicity is increased by the presence of two different drugs. As shown in Fig. 10(A), which illustrates cell death after $72 \mathrm{~h}$ of incubation with different batches of nanoparticles, NP exhibited essentially no cytotoxic activity (control). The corresponding data for NP3RhB confirmed that the active cap was released, with good cytotoxicity demonstrated against MCF-7 cells. Finally, NP3CPT showed excellent tumour elimination, with more than $90 \%$ of cell death from a concentration of $50 \mu \mathrm{g} \mathrm{mL} \mathrm{m}^{-1}$ and up to $99 \%$ of cell death at $100 \mu \mathrm{g} \mathrm{mL} \mathrm{mL}^{-1}$. The $\mathrm{IC}_{50}$ of NP3CPT under these conditions is $4 \mu \mathrm{g} \mathrm{mL} \mathrm{m}^{-1}$, a particularly low value, which demonstrates the complementary and concomitant activity of the multidrug approach employed here, where each drug attacks the cells via different and complementary biological pathways.
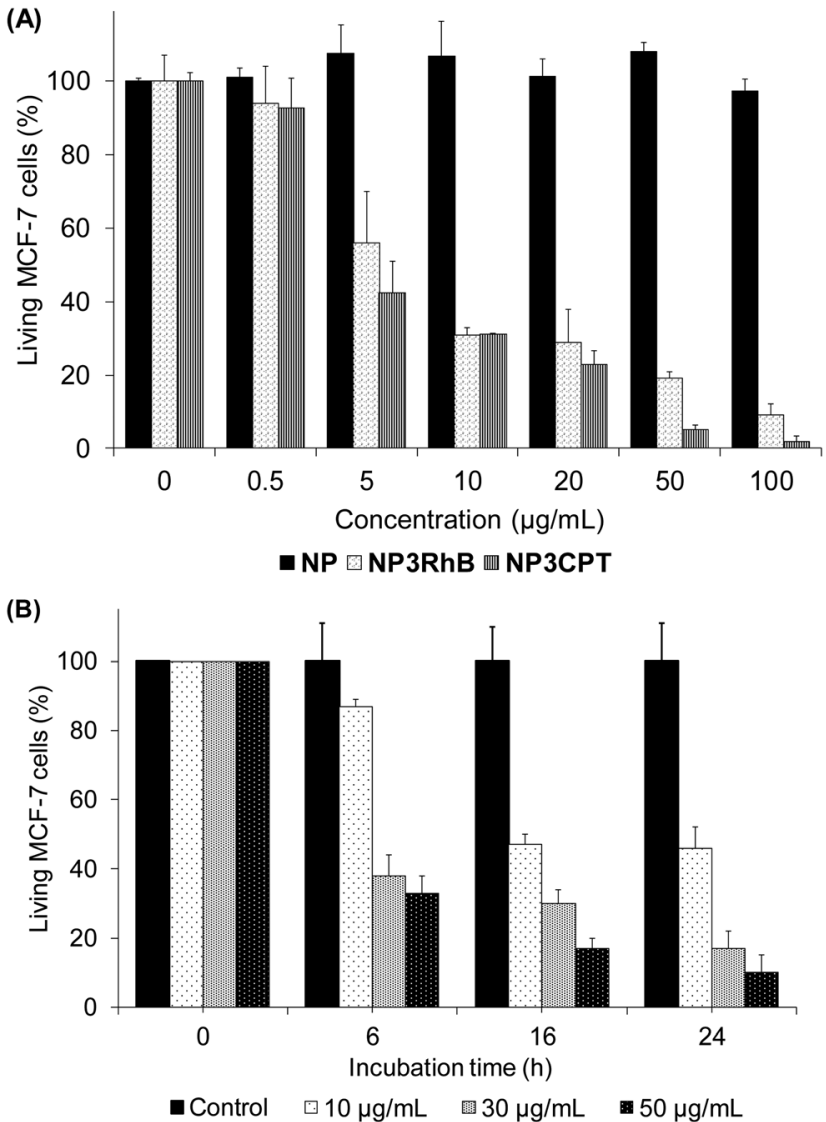

Fig. 10 (A) Cytotoxicity test of NP, NP3RhB and NP3CPT on MCF-7 cells after $72 \mathrm{~h}$ of incubation. (B) Cytotoxic effect of NP3CPT on MCF-7 as a function of incubation time and concentration. Error bars show standard deviation.

Following this promising result, the activity of NP3CPT on MCF-7 cells was determined at shorter times. For this, incubations with NP3CPT at 10,30 and $50 \mu \mathrm{g} \mathrm{mL} \mathrm{m}^{-1}$ were performed and followed by MTT assays after 6, 16 and $24 \mathrm{~h}$. The results presented in Fig. 10(B) revealed that the action of NP3CPT was relatively fast. Indeed, after only $6 \mathrm{~h}$ of incubation, MTT assay results already showed a significant inhibition of cell growth. Moreover, after $24 \mathrm{~h}$ the results obtained were close to those observed in the previous study carried out after $72 \mathrm{~h}$ of incubation. These data confirm that essentially complete apoptosis of the MCF-7 cells can be achieved, in vitro, with the NP3CPT system within $24 \mathrm{~h}$.

\section{Conclusions}

Herein, a silica-based nanocarrier system in which CPT was loaded within the pores and a 5-FU analogue complexed on the surface as a pore-capping agent has been shown to be a viable system for environmentally-triggered, sequential release of these anti-cancer drugs for successful eradication of breast cancer cells. The nanosystem has been shown to respond to changes in environmental $\mathrm{pH}$, thus enabling the delivery of a multi-drug payload within the lysosomal compartment of cancer cells. In contrast, almost no release of the cytotoxic 
compounds was observed under normal physiological conditions, thus minimising toxic side-effects in normal tissue and within the blood stream.

The efficacy of this approach was demonstrated through in vitro trials, involving the consecutive delivery of the 5-FU derivative (rapid release) and CPT (diffusion-limited release) in MCF-7 breast cancer cells.

Under the conditions used in this study, essentially complete breast cancer cell apoptosis was observed within $72 \mathrm{~h}$. This result highlights the attractive synergistic effect of the two drugs acting in tandem against tumoral cells. Additionally, the loading of the two synergistic drugs into silica nanocarriers offers the significant advantage of preventing the debilitating side effects usually associated with combination cancer therapy.

It is envisaged that the approach developed in this work could also be extended to multi-combinatorial therapy, involving the sequential release of three or more drugs.

\section{Conflicts of interest}

There are no conflicts to declare.

\section{Acknowledgements}

We are grateful to the CNRS and the French Higher Education and Research Ministry. This work was partially funded with a young researcher grant from the French National Research agency (ANR-2010-JCJC-1006-01). We acknowledge the imaging facility MRI, member of the national infrastructure FranceBioImaging supported by the French National Research Agency (ANR-10-INBS-04, "Investments for the future"). We thank Prof. Fuyuhiko Tamanoi for access to EDX-HRTEM at Kyoto University and help and support in pH-release testing.

\section{Notes and references}

1 Q. Hu, W. Sun, C. Wang and Z. Gu, Adv. Drug Delivery Rev., 2016, 98, 19-34.

2 R. Bayat Mokhtari, T. S. Homayouni, N. Baluch, E. Morgatskaya, S. Kumar, B. Das and H. Yeger, Oncotarget, 2017, 8, 38022-38043.

3 P. Sharma and James P. Allison, Cell, 2015, 161, 205-214.

4 O. C. Farokhzad and R. Langer, Adv. Drug Delivery Rev., 2006, 58, 1456-1459.

5 N. Kolishetti, S. Dhar, P. M. Valencia, L. Q. Lin, R. Karnik, S. J. Lippard, R. Langer and O. C. Farokhzad, Proc. Natl. Acad. Sci. U. S. A., 2010, 107, 17939-17944.

6 A. Jhaveri, P. Deshpande and V. Torchilin, J. Controlled Release, 2014, 190, 352-370.

7 J. K. Patra, G. Das, L. F. Fraceto, E. V. R. Campos, M. d. P. Rodriguez-Torres, L. S. Acosta-Torres, L. A. DiazTorres, R. Grillo, M. K. Swamy, S. Sharma, S. Habtemariam and H.-S. Shin, J. Nanobiotechnol., 2018, 16, 71.

8 R. K. Singh, J. C. Knowles and H.-W. Kim, J. Tissue Eng., 2019, 10, 2041731419877528.
9 I. I. Slowing, B. G. Trewyn, S. Giri and V. S.-Y. Lin, Adv. Funct. Mater., 2007, 17, 1225-1236.

10 I. I. Slowing, J. L. Vivero-Escoto, C.-W. Wu and V. S. Y. Lin, Adv. Drug Delivery Rev., 2008, 60, 1278-1288.

11 J. M. Rosenholm, V. Mamaeva, C. Sahlgren and M. Lindén, Nanomedicine, 2012, 7, 111-120.

12 Y. Wang, Q. Zhao, N. Han, L. Bai, J. Li, J. Liu, E. Che, L. Hu, Q. Zhang, T. Jiang and S. Wang, Nanomedicine, 2015, 11, 313-327.

13 J. Wen, K. Yang, F. Liu, H. Li, Y. Xu and S. Sun, Chem. Soc. Rev., 2017, 46, 6024-6045.

14 M. Vallet-Regí, F. Balas and D. Arcos, Angew. Chem., Int. Ed., 2007, 46, 7548-7558.

15 C.-H. Lee, S.-H. Cheng, I.-P. Huang, J. S. Souris, C.-S. Yang, C.-Y. Mou and L.-W. Lo, Angew. Chem., Int. Ed., 2010, 49, 8214-8219.

16 L. Yuan, Q. Tang, D. Yang, J. Z. Zhang, F. Zhang and J. Hu, J. Phys. Chem. C, 2011, 115, 9926-9932.

17 C. Théron, A. Gallud, S. Giret, M. Maynadier, D. Grégoire, P. Puche, E. Jacquet, G. Pop, O. Sgarbura, V. Bellet, U. Hibner, J. I. Zink, M. Garcia, M. Wong Chi Man, C. Carcel and M. Gary-Bobo, RSC Adv., 2015, 5, 64932-64936.

18 Q. Zhang, F. Liu, K. T. Nguyen, X. Ma, X. Wang, B. Xing and Y. Zhao, Adv. Funct. Mater., 2012, 22, 5144-5156.

19 A. Rahikkala, S. A. P. Pereira, P. Figueiredo, M. L. C. Passos, A. R. T. S. Araújo, M. L. M. F. S. Saraiva and H. A. Santos, Adv. Biosyst., 2018, 2, 1800020.

20 Z.-Y. Li, Y. Liu, X.-Q. Wang, L.-H. Liu, J.-J. Hu, G.-F. Luo, W.-H. Chen, L. Rong and X.-Z. Zhang, ACS Appl. Mater. Interfaces, 2013, 5, 7995-8001.

21 F. Muhammad, M. Guo, A. Wang, J. Zhao, W. Qi, Y. Guo and G. Zhu, J. Colloid Interface Sci., 2014, 434, 1-8.

22 M. C. Llinàs, G. Martínez-Edo, A. Cascante, I. Porcar, S. Borrós and D. Sánchez-García, Drug Delivery, 2018, 25, 1137-1146.

23 S. Giret, C. Théron, A. Gallud, M. Maynadier, M. Gary-Bobo, M. Garcia, M. Wong Chi Man and C. Carcel, Chem. - Eur. J., 2013, 19, 12806-12814.

24 L. F. Liu, S. D. Desai, T.-K. Li, Y. Mao, M. E. I. Sun and S.-P. Sim, Ann. N. Y. Acad. Sci., 2000, 922, 1-10.

25 D. B. Longley, D. P. Harkin and P. G. Johnston, Nat. Rev. Cancer, 2003, 3, 330-338.

26 S. Guichard, I. Hennebelle, R. Bugat and P. Canal, Biochem. Pharmacol., 1998, 55, 667-676.

27 Q. Luo, P. Wang, Y. Miao, H. He and X. Tang, Carbohydr. Polym., 2012, 87, 2642-2647.

28 C. Théron, A. Birault, M. Bernhardt, L. M. A. Ali, C. Nguyen, M. Gary-Bobo, J. R. Bartlett, M. Wong Chi Man and C. Carcel, J. Sol-Gel Sci. Technol., 2019, 89, 45-55.

29 M. K. Trivedi, R. M. Tallapragada, A. Branton, D. Trivedi, G. Nayak, R. K. Mishra and S. Jana, J. Mol. Pharm. Org. Process Res., 2015, 3, 128-134.

30 M. A. Mondragón, V. M. J. Castaño, M. C. A. Garcia and S. Téllez, Vib. Spectrosc., 1995, 9, 293-304.

31 P. Fisher, Wildl. Soc. Bull., 1999, 27, 318-329. 